OPEN ACCESS

Edited by:

Tamás Laskay,

University of Lübeck, Germany

Reviewed by:

Christian Bogdan,

University of Erlangen-Nuremberg,

Germany

Werner Solbach,

University of Lübeck, Germany

*Correspondence:

Xiaoying Liu

liuxiaoying@ahmu.edu.cn

Specialty section:

This article was submitted to Microbial Immunology,

a section of the journal

Frontiers in Microbiology

Received: 14 December 2019

Accepted: 24 June 2020

Published: 15 July 2020

Citation:

Li X, Körner H and Liu X (2020)

Susceptibility to Intracellular Infections: Contributions of TNF

to Immune Defense.

Front. Microbiol. 11:1643. doi: 10.3389/fmicb.2020.01643

\section{Susceptibility to Intracellular Infections: Contributions of TNF to Immune Defense}

\author{
Xinying Li ${ }^{1,2}$, Heinrich Körner ${ }^{3}$ and Xiaoying Liu ${ }^{1,2 *}$ \\ 1 Translational Research Institute, Academy of Medical Science, Henan Provincial People's Hospital, Zhengzhou, China, \\ ${ }^{2}$ School of Life Sciences, Anhui Medical University, Hefei, China, ${ }^{3}$ Key Laboratory of Anti-inflammatory \\ and Immunopharmacology, Institute of Clinical Pharmacology, Ministry of Education, Engineering Technology Research \\ Center of Anti-inflammatory and Immunodrugs in Anhui Province, Anhui Medical University, Hefei, China
}

An interesting puzzle is the fact that an infection of a tumor necrosis factor $\alpha$ (TNF)deficient host with pathogens such as bacteria or parasites that reside intracellularly inevitably ends fatally. Is this due to one specific role of TNF in the immune defense or are different functions responsible for this outcome? In this review we provide an update of the functions of TNF in the defense against the intracellular pathogens Listeria monocytogenes, Mycobacterium tuberculosis, and Leishmania major. Furthermore, we discuss the role of TNF in the generation of proinflammatory macrophages in mouse models of infection and summarize briefly the potential consequences of anti-TNF treatment for infectious diseases.

Keywords: TNF, macrophage polarization, Listeria monocytogenes, Mycobacterium tuberculosis, Leishmania major

\section{INTRODUCTION}

The increased susceptibility of a host organism to pathogens has many underlying factors. These range from environmental causes such as the effects of malnourishment on the immune system through to intrinsic differences resulting from genetics. Some susceptibility genes have been relatively easy to identify since the functions of their encoded proteins are directly associated with pathogenic resistance. For example, the natural resistance-associated macrophage protein (Nramp) has been shown to be crucial in the fight of macrophages against intracellular pathogens including mycobacteria, salmonella, and leishmania (Vidal et al., 1993). Susceptibilities based on deficiency or dysregulation of cytokines are usually more complex because these can originate from direct or indirect activities, or secondary interactions with the host immune system. In this respect, the cytokine tumor necrosis factor $\alpha$ (TNF) is an excellent example which has been studied extensively because of its involvement in susceptibilities to pathogens. This cytokine was named for its ability to induce haemorrhagic necrosis in murine Meth A sarcomas (Carswell et al., 1975). Macrophages activated by endotoxin were identified as the major source of TNF (Mannel et al., 1980) with natural killer cells and $\mathrm{T}$ lymphocytes constituting the predominant secondary sources in response to various challenges (Fremond et al., 2005). TNF plays a central role in initiation and promotion of inflammation (Old, 1985; Körner and Sedgwick, 1996; Sedgwick et al., 2000), thus dysregulated TNF production and function are associated with the pathogenesis of inflammatory diseases such as 
rheumatoid arthritis (RA), inflammatory bowel disease, systemic lupus erythematosus, ankylosing spondylitis, and multiple sclerosis (Kollias et al., 1999; Kollias, 2005). To date, biologicals which effectively neutralize TNF activity have not shown utility for multiple sclerosis, but have had varying degrees of efficacy for other conditions. The antagonists include antiTNF monoclonal antibodies and an anti-TNF receptor-Fc fusion protein. Unfortunately, due to the prominent pro-inflammatory function of TNF, administration of anti-TNF agents is associated with an increased risk of an infection, especially by intracellular pathogens (Efimov et al., 2009) and malignancies (Bongartz et al., 2006). In this review, we will focus on the role of TNF in intracellular infections by bacterial and parasitic pathogens such as Listeria monocytogenes, Mycobacterium tuberculosis, and Leishmania spp. Since macrophages are the predominant host cells of many of those infections, this cell type and the role of TNF in its differentiation will be discussed in particular.

\section{EFFECTS OF TNF IN Listeria monocytogenes INFECTION}

Listeria monocytogenes is an intracellular, food-borne, grampositive pathogen that causes listeriosis, which is characterized by gastroenteritis, septicaemia, and meningitis. Infections have high hospitalization and fatality rates in immunocompromised patients and can result in spontaneous abortions during pregnancy (Gellin and Broome, 1989; Schuchat et al., 1991). After ingestion, L. monocytogenes invades the blood stream and lymphatic system, and ultimately disseminates to spleen, liver and potentially, the central nervous system (Schuchat et al., 1991). In this context, L. monocytogenes has emerged as a focal point of research into genetics and strategies of intracellular pathogens (Glaser et al., 2001). Whilst it can infect nonphagocytic cells, including hepatocytes, enterocytes, endothelial cells, and fibroblasts, and can also be internalized into phagocytes such as macrophages through phagocytosis (Vazquez-Boland et al., 2001). Once internalized, the bacterium may be killed or alternatively can escape from the phagolysosome into the cytoplasm and initialize infection of other host cells (Cossart and Mengaud, 1989; Tilney and Portnoy, 1989).

A control of L. monocytogenes infection requires an activation of toll-like receptors (TLRs) and a functional MyD88 pathway which leads to the expression of proinflammatory cytokines, including TNF and IL-12 (Tripp et al., 1993). The pathogen also activates AIM2, NLRP3, NLRC4, NLRC5, NLRC6 inflammasomes and induces the release of IL-1 $\beta$ and IL-18 (Theisen and Sauer, 2016). The initial boost of these pro-inflammatory cytokines is important because it triggers IFN- $\gamma$ secretion by $\mathrm{T}$ cells which has been shown to be crucial for macrophage activation and microbicidal activity (Buchmeier and Schreiber, 1985; Dalton et al., 1993). TNF contributes to protection against infection in an experimental model (Havell, 1987) and acts as co-stimulator for the crucial production of IFN- $\gamma$ (Tripp et al., 1993). It is also involved in a $\mathrm{T}$ cell-independent pathway that leads to macrophage activation as demonstrated in infection of severe combined immunodeficiency mice (Bancroft et al., 1989). Moreover, the contribution of TNF was shown in gene-deficient mouse models where either TNF or TNF Receptor 1 (R1)-deficient mice quickly succumbed to $L$. monocytogenes rather than recovering after a few days as occurs in control mice (Pfeffer et al., 1993; Rothe et al., 1993; Pasparakis et al., 1996). TNF is generated as a membrane protein before cleavage and release and notably, knock-in of an uncleavable form of TNF controlled L. monocytogenes infection at a low dose suggesting membrane bound TNF in macrophages functions to some extent in anti-bacterial responses (Torres et al., 2005; Table 1).

Human RA patients that were treated with anti-TNF biologicals had an increased general infection rate (Listing et al., 2005). This was confirmed in a meta-analysis of the literature (Bongartz et al., 2006) which has been discussed controversially (Dixon and Silman, 2006). In a second national prospective observational study of 7,664 anti-TNF-treated patients that used data from the British Society for Rheumatology Biologics Register with severe RA, 19 serious infections with intracellular pathogens were isolated without a preference for either infliximab or adalimumab (Dixon et al., 2006).

More specifically, serious infections with L. monocytogenes after treatment with either infliximab or etanercept were identified in the FDA Adverse Event Reporting system in a small number of patients. In 14 of the total 15 cases were associated with infliximab treatment (Slifman et al., 2003). In a more recent study that used the same source from 2004 to 2011, 266 cases of listeriosis could be identified with the majority of patients receiving infliximab $(77.1 \%)$, followed by etanercept $(11.7 \%)$, and adalimumab (9.8\%) (Bodro and Paterson, 2013). The differences between infliximab and etanercept activity are interesting conundrums and are most likely due to the different modes of action between the two biologicals (Fallahi-Sichani et al., 2012). Infliximab is chimeric monoclonal antibody fused with human IgG1 targeting TNF while etanercept is a fusion protein with a human IgG1 Fc tail and TNFR2, but only infliximab causes monocytopenia (Lugering et al., 2001) and can induce apoptosis in intestinal T cells (Van Den Brande et al., 2003).

\section{TNF IN M. tuberculosis INFECTION}

The infectious disease tuberculosis (TB) is caused by an infection with $M$. tuberculosis and constitutes a leading cause of mortality worldwide (Kaufmann et al., 2005). With multidrug resistant strains spreading, and in combination with HIV infection, tuberculosis is a global health threat (Kaufmann, 2001). Predominantly, healthy individuals exposed to M. tuberculosis will not develop clinical disease symptoms. Only $10 \%$ of infections eventually show clinical signs of tuberculosis (O'garra et al., 2013). In the lungs, neutrophils and alveolar macrophages are crucial in initiating an early inflammatory response (Seiler et al., 2003). This early response is essential for the formation of an heterogeneous granuloma that is composed of macrophages, dendritic cells, neutrophils, NK cells, B and T cells, and contains the bacteria (Guirado and Schlesinger, 2013). 
TABLE 1 | Consequences of interference with TNF signaling in L. monocytogenes infection.

\begin{tabular}{|c|c|c|c|c|}
\hline Pathogen & $\begin{array}{l}\text { Genetic } \\
\text { background/treatment }\end{array}$ & Infection site & Phenotype & References \\
\hline \multirow[t]{6}{*}{ L. monocytogenes } & C57BL/6-TNF $-/-$ & $\mathrm{IP}$ & Susceptible, increased bacterial load in spleen, liver & Pasparakis et al., 1996; Li et al., 2017 \\
\hline & C57BL/6-MN-TNF-/- & IV & Susceptible to low-mediate dose of infection & Grivennikov et al., 2005 \\
\hline & C57BL/6-T cells-TNF-/- & IV & Susceptible to high dose of infection & Grivennikov et al., 2005 \\
\hline & C57BL/6-TNFR1-/- & IV & Susceptible, increased bacterial load in spleen, liver & Pfeffer et al., 1993; Rothe et al., 1993 \\
\hline & C57BL/6-TNFR2-/- & IV & $\begin{array}{l}\text { Susceptible to high dose of infection, normal T cell } \\
\text { development }\end{array}$ & Erickson et al., 1994 \\
\hline & rHUTNF & IV & Resistant to lethal bacterial infection & Desiderio et al., 1989 \\
\hline
\end{tabular}

IP, intraperitoneal; IV, intravenous; TNF, tumor necrosis factor $\alpha$; MN, macrophages/neutrophils; rHuTNF, recombinant human TNF.

Neutralization of TNF or TNFR1-deficiency due to a genetic modification in mouse models results in high susceptibility to M. tuberculosis infection with increased bacterial loads (Flynn et al., 1995). This increase in susceptibility is exclusively driven by the soluble TNF-TNFR1 axis (Flynn et al., 1995). In contrast, membrane-bound TNF and TNFR2 play minor roles in antimycobacterial defense (Jacobs et al., 2000; Olleros et al., 2002).

Surprisingly, the underlying cause for the increased sensitivity of TNF-deficient mice is the lack of organized granulomas. Despite an accumulation of lymphocytes in the perivascular areas of the lung, they fail to collocate with inflammatory macrophages at the site of M. tuberculosis infection (Bean et al., 1999). Indeed, at the late stage of infection of TNFRp $55^{-/-}$mice, a lethal disintegration of the poorly formed granulomas occurs (Ehlers et al., 2000; Table 2).

Along with cytokines such as TNF, inducible nitric oxide synthase (iNOS) has also been produced as an important effector in host defense against $M$. tuberculosis. A role of iNOS was first shown using inhibitors of iNOS which increased the bacterial burden and also the tissue injury of $M$. tuberculosis infection (Chan et al., 1995). Moreover, findings in genetically deficient iNOS $^{-1-}$ mice confirming iNOS was an important host gene locus for susceptibility (Macmicking et al., 1997). Interestingly, experiments in $\mathrm{TNF}^{-/-}$mice indicated that the role of iNOS in resistance was not as dominant as had been suggested. Despite TNF-deficient mice failing to establish protective granulomas and rapidly succumbing to M. tuberculosis infection, they were able to produce normal amounts of iNOS (Bean et al., 1999). The view that iNOS plays a limited role in protection was supported in experiments comparing IFN- $\gamma$-deficient mice to NNOS $^{-/-}$mice. In the early stage of a low dose infection model, IFN- $\gamma$ expression was crucial in controlling disease, whereas $\mathrm{iNOS}^{-/-}$mice controlled M. tuberculosis infection almost as effectively as wild-type mice (Cooper et al., 2000). A caveat of these findings involves different experimental conditions, in particular, differences in routes of infection, strains of pathogen and analysis time points. Furthermore, at the later stages of infection, IFN- $\gamma$-deficient mice succumbed to disease and the reduced iNOS expression in macrophage suggests that iNOS was important to recovery.

While host susceptibility is important, another key factor determining the severity of infections is bacterial virulence.
Experiments with virulent (H37Rv) and attenuated (H37Ra) M. tuberculosis strains in resistant and iNOS $^{-/-}$mouse strains showed that the role of iNOS in protection depended to a large extent on the virulence of the infecting strain. The attenuated strain was controlled by both mouse strains while the iNOS ${ }^{-/-}$ mice showed exacerbated infection with the virulent strain (Beisiegel et al., 2009).

This limited role of iNOS as protective factor has also been shown in reactivation experiments. $\mathrm{CD} 4^{+} \mathrm{T}$ cell depletion caused reactivation despite unimpaired iNOS expression implying other macrophage factors in host defense (Scanga et al., 2000) and neutralization of TNF after successful treatment that reduced the number of pathogens to an undetectable level resulted in a rapid reactivation (Botha and Ryffel, 2003).

About one quarter to one third of the human population carries a latent $M$. tuberculosis infection that is encapsulated in granulomas and can stay dormant for the entire life span of the carrier (Getahun et al., 2015). Reactivation of tuberculosis in patients due to anti-TNF treatment has been recognized as a major complication (Keane et al., 2001) and it became clear that a difference existed between treatment with antibody- or receptor-based biologicals (Ehlers, 2005). While the underlying mechanisms are still not entirely clear, computer modeling shows that binding to membrane TNF is critical for an impairment of granuloma formation and that the differences between drugs in binding kinetics and vascular permeability are crucial (Fallahi-Sichani et al., 2012).

\section{TNF IN CUTANEOUS LEISHMANIASIS}

The parasite Leishmania spp. causes cutaneous leishmaniasis which is common in South America, Sub-Saharan Africa, the Mediterranean, the Middle-East and parts of South-East Asia with about one million new cases annually (Reithinger et al., 2007; Ready, 2014). Leishmaniasis has been identified as a neglected tropical disease by the world health organization and lacks an effective vaccine (Kaye and Aebischer, 2011). The transfer of Leishmania spp. promastigotes into the skin occurs during a blood meal of female phlebotomine sand flies (Sacks and Perkins, 1984). Cutaneous leishmaniasis is the most common form of leishmaniasis with benign self-healing skin lesions that eventually resolve, while muco-cutaneous leishmaniasis leads 
TABLE 2 | Consequences of interference with TNF signaling in M. tuberculosis infection.

\begin{tabular}{|c|c|c|c|c|}
\hline Pathogen & $\begin{array}{l}\text { Genetic } \\
\text { background/treatment }\end{array}$ & Infection site & Phenotype & References \\
\hline \multirow[t]{6}{*}{ M. tuberculosis } & C57BL/6-TNF-/- & IV & Susceptible, delayed granuloma formation in liver & Bean et al., 1999 \\
\hline & C57BL/6-memTNF $-/-$ & Aerosol & Resistant to low dose of bacterial infection & Saunders et al., 2005 \\
\hline & C57BL/6-TNFR1 ${ }^{-/-}$ & IV & $\begin{array}{l}\text { Susceptible, high bacterial load in spleen, liver, lungs, delayed } \\
\text { granuloma formation }\end{array}$ & Flynn et al., 1995 \\
\hline & C57BL/6-TNFR2-/- & IV & Less susceptible, normal granuloma formation & Jacobs et al., 2000 \\
\hline & Anti-TNF mAb & IV & Susceptible, high bacterial load in spleen, liver, lungs & Flynn et al., 1995 \\
\hline & $\begin{array}{l}\text { Anti-TNF mAb in } \\
\text { quiescent phase }\end{array}$ & IV & Reactivation of infection, disorganization of granuloma & Mohan et al., 2001 \\
\hline
\end{tabular}

$I V$, intravenous; TNF, tumor necrosis factor $\alpha$; mAb, monoclonal antibody; memTNF, membrane TNF.

to complications that result in permanent disfigurement of the patients. Finally, the visceral leishmaniasis represents the most severe form of leishmaniasis and presents with fever, serious weight loss, hypergammaglobulinemia, and pancytopenia (Reithinger et al., 2007).

Leishmania spp. parasites initially encounter neutrophils in the skin and are phagocytosed (Laskay et al., 2003; Van Zandbergen et al., 2004; Peters et al., 2008). After apoptosis, the parasitized neutrophils are then taken up by macrophages (Pearson et al., 1983; Van Zandbergen et al., 2004). Amastigotes can find shelter from an immune response and multiply inside the macrophage phagolysosome while tapping into the macrophage metabolism for nutrients (Bogdan et al., 1996; Bogdan and Rollinghoff, 1998).

However, once the pro-inflammatory cytokines IFN- $\gamma$ and TNF become available, macrophages begin producing microbicidal effector molecules such as iNOS and can eliminate the contained pathogens (Bogdan et al., 1990; Green et al., 1990; Liew et al., 1990a; Hu et al., 2017).

The role of TNF in defense against Leishmania major has been intensively investigated in experimental cutaneous leishmaniasis in vivo models using mice deficient in TNF ligand or TNF receptors. Deficiency of soluble TNF leads to a high parasite burden, unresolved lesions and fatal disease, despite a Th1-response (Wilhelm et al., 2001; Fromm et al., 2015; Hu et al., 2017). Counterintuitively, TNFR1-deficient mice show an elevated parasite load but eventually resolve lesions and eliminate the L. major parasites (Vieira et al., 1996; Fromm et al., 2015). Moreover, TNFR2-deficient (Nashleanas et al., 1998; Fromm et al., 2015) and membrane TNF-deficient (Allenbach et al., 2008; Fromm et al., 2015) are resistant to L. major infection, indicating that soluble but not membrane TNF plays the key role in the defense against L. major (Table 3).

The expression of iNOS after activation by IFN $\gamma$ and TNF has been shown to be central for an effective host response (Bogdan et al., 1990; Green et al., 1990; Stenger et al., 1994). In the early stages after parasite inoculation, iNOS expression is induced by IFN $\alpha / \beta$ signaling in the skin to prevent the dissemination of parasites (Diefenbach et al., 1998). IFN- $\gamma$ expression by CD4 ${ }^{+}$ $\mathrm{T}$ cells also promotes the expression of iNOS (Stenger et al., 1994) which generates a high NO concentration in the tissue and effectively controls Leishmania expansion (Olekhnovitch et al., 2014). After clinical resolution of the lesions, the disease will reappear and Leishmania proliferate rapidly if iNOS activity is inhibited (Stenger et al., 1996).

Moreover, cases of recurrent leishmaniasis have been reported in patients receiving anti-TNF agents including infliximab, adalimumab and in very few cases, etanercept (Zanger et al., 2012; Guedes-Barbosa et al., 2013). The majority of recurrences has been observed in countries with an endemic reservoir including Mediterranean countries (Marcoval et al., 2017) or in holiday makers returning from endemic areas (Neumayr et al., 2013).

\section{POLARIZATION EFFECTOR MECHANISMS IN MACROPHAGES}

\section{Macrophage Polarization}

Peripheral monocytes and tissue macrophages display a remarkable plasticity in vivo (Gordon and Martinez, 2010; Varol et al., 2015). Depending on the nature and kinetics of a specific inflammatory response and a given cytokine environment, monocytes that enter tissues can rapidly develop into inflammatory effector M1 macrophages, or act as antigenpresenting cells (Murray, 2017). Subsequently, after the elimination of the inflammatory cues peripheral monocytes differentiate directly to M2 macrophages with a repair phenotype (M2 polarization) (Murray et al., 2014).

The definition of M1 and M2 macrophages as separate macrophage subpopulations is a concept based on in vitro experiments (Gordon, 2003). M1 and M2 macrophages represent the two extremes of a spectrum of physiological responses of macrophages to a very limited set of stimuli. The cytokine IFN $\gamma$ which is characteristic of a $\mathrm{T}$ helper (Th) 1 response, polarized macrophages to a pro-inflammatory M1 phenotype. A similar outcome was also achieved by an engagement of TLRs (El Kasmi et al., 2008). In contrast, the Th2-type cytokines IL-4, IL-10, and/or IL-13 resulted in an alternative activation driven by the transcription factor STAT6 (Gordon and Martinez, 2010; Murray et al., 2014; Murray, 2017). The separate expression signatures of M1 and M2 macrophages were evident and could easily be distinguished (Martinez et al., 2013; Murray, 2017).

A major physiological difference in murine macrophages is the presence of the enzyme iNOS in M1 macrophages, which metabolizes L-arginine to nitric oxide (NO) and to reactive nitrogen species, and to citrulline which can be reused via the 
TABLE 3 | Consequences of interference with TNF signaling in L. major infection.

\begin{tabular}{|c|c|c|c|c|}
\hline Pathogen & Genetic background/treatment & Infection site & Phenotype & References \\
\hline \multirow[t]{5}{*}{ L. major } & C57BL/6-TNF ${ }^{-/-}\left(\mathrm{B}^{\mathrm{T}} \mathrm{TNF}^{-/-}\right)$ & SC & $\begin{array}{l}\text { Extremely susceptible, high parasite burden, fail to } \\
\text { resolve lesions, produce iNOS but no NO; higher } \\
\text { ratio of } \mathrm{iNOS}^{+} \mathrm{Arg}^{+}{ }^{+} \text {versus iNOS }{ }^{+} \text {macrophages }\end{array}$ & $\begin{array}{l}\text { Körner et al., 1997; Fromm et al., } \\
\text { 2012; Schleicher et al., 2016; Hu } \\
\text { et al., } 2018\end{array}$ \\
\hline & C57BL/6-memTNF ${ }^{\Delta / \Delta}$ & SC & Resistant, similar to wild-type & $\begin{array}{l}\text { Allenbach et al., 2008; Fromm et al., } \\
2012\end{array}$ \\
\hline & C57BL/6 TNFR1 ${ }^{-/-}$ & SC & $\begin{array}{l}\text { Susceptible, high parasite burden, fail to resolve } \\
\text { lesions, survive infection in many cases }\end{array}$ & $\begin{array}{l}\text { Vieira et al., 1996; Nashleanas et al., } \\
\text { 1998; Fromm et al., } 2012\end{array}$ \\
\hline & $\begin{array}{l}\text { C57BL/6-TNFR2 } 2^{-/-} \\
\text {TNFR1/R2 } \\
\text { TN- }\end{array}$ & SC & Resistant, similar to wild-type & $\begin{array}{l}\text { Nashleanas et al., 1998; Fromm } \\
\text { et al., } 2012\end{array}$ \\
\hline & rTNF & SC & Smaller lesion size, lower parasite counts & Titus et al., 1989; Liew et al., 1991 \\
\hline
\end{tabular}

TNF, tumor necrosis factor $\alpha$; memTNF, membrane TNF; rTNF, recombinant TNF; SC, subcutaneous.

citrulline-NO cycle (Rath et al., 2014). High level expression of iNOS and the production of large amounts of NO provides M1 macrophages with the capacity to kill pathogens (Bogdan, 2015). Furthermore, M1 macrophages have been characterized by an expression of pro-inflammatory cytokines that aligns them with a Th1 response (TNF, type I IFN, IL-1 $\beta$, IL-6, IL-12, IL-18, IL-23) (Murray et al., 2014; Murray, 2017).

In mouse models, M2 macrophages are characterized by expression of arginase (Arg1), an enzyme which hydrolyzes $\mathrm{L}$-arginine to ornithine and urea. The arginase pathway facilitates the downstream synthesis pathways for polyamine and proline via ornithine, which M2 macrophages can utilize for tissue repair. Importantly, since Arg1 utilizes the same substrate as iNOS, Arg1 naturally limits L-arginine availability for NO synthesis by iNOS (Rath et al., 2014). M2 macrophages are aligned with the presence of Th2 cytokines such as IL-4, IL-13, and are associated with a response to parasitic diseases and late stages of an inflammatory immune response that supports wound healing and show in mouse models an expression of IL-10 and IL6 (Murray et al., 2014). Indeed, arginine metabolic pathways cross-inhibit each other on the level of the respective arginine break-down products (Rath et al., 2014). This can have important effects for macrophage polarization and the immune response as will be discussed later (Rapovy et al., 2015; Schleicher et al., 2016).

While TNF is a major product of activated macrophages it also shows a strong influence on the activation and development of these cells. IFN- $\gamma$-induced macrophages express TNF in autocrine or paracrine manner (Mosser and Edwards, 2008) which synergistically enhances the expression of proinflammatory cytokines and microbicidal effector mechanisms (Bogdan et al., 1990; Liew et al., 1990a).

A single pulse of TNF produces an extended yet transient activation of the NF- $\kappa$ B pathway in macrophages (Hoffmann et al., 2002; Kalliolias and Ivashkiv, 2016) which, contingent on timing, results in induction of gene expression dependent on chromatin accessibility and availability of accessory proteins (Kalliolias and Ivashkiv, 2016). TNF activities are widespread but are predominantly pro-inflammatory in early stage immune responses (Kusnadi et al., 2019), serving to actively suppress M2 polarization in tumor associated macrophages and infection models (Kratochvill et al., 2015; Schleicher et al., 2016). The TNF-mediated restriction of M2 polarization is viewed to be an important contribution to an effective immune defense. Consequently, an absence of TNF or the blocking of its activities has consequences for the immune response to intracellular pathogens as macrophages are not only important effector cells but also targets of various species of intracellular pathogens. Given that macrophages are the primary targets for various species of intracellular pathogens, the following section discusses the importance of TNF on macrophage activation during such infections.

\section{Listeria monocytogenes}

Nitric oxide is one of the central effector molecules for defense against L. monocytogenes infection (Beckerman et al., 1993; Leenen et al., 1994). For example, mice treated with iNOS inhibitors show an exacerbated infection in spleen and liver (Boockvar et al., 1994). Macrophages have been identified as the source of both NO and TNF in experimental L. monocytogenes infection. After infection monocytes are recruited to the spleen via CCR2 (Kurihara et al., 1997; Serbina et al., 2003) and differentiate into TNF/iNOS-producing CD11b $b^{\text {int }} / \mathrm{CD} 11 c^{\text {int }}$ dendritic cells (TipDCs). These cells are not required for in vivo T-cell priming but represent an effector arm of the innate immune system producing iNOS and TNF that elicit protective immune responses against $L$. monocytogenes (Serbina et al., 2003). Interestingly, iNOS-deficient mice are able to eliminate infections with a virulent $L$. monocytogenes strain despite a higher bacterial burden. However, mice with a double KO of iNOS in combination with gp91 phagocyte oxidase (phox) succumbed to L. monocytogenes infection, demonstrating that other effector mechanisms can compensate for an absence of $\mathrm{NO}$ (Shiloh et al., 1999). In the absence of TNF, TipDC-equivalent cells had an increased expression of Arg1 and harbored more bacteria (Li et al., 2017).

\section{Mycobacterium tuberculosis}

Macrophages respond differently to infection by different genotypes of $M$. tuberculosis. However, a common signature is the expression of various amounts of iNOS, IL-1 $\beta$, TNF, and IL-12 which corresponds to an M1 program (Chacon-Salinas et al., 2005). The concurrent exposure of macrophages to the pathogen and IFN $\gamma$ was used as model to reveal the underlying transcriptomic changes, with these experiments demonstrating 
that iNOS and/or phagocyte oxidase (phox) had a central role in this reprogramming (Ehrt et al., 2001). This early stage M1 polarization was also demonstrated in alveolar macrophages as a component of granulomas in mice (Redente et al., 2010) and also in studies of human TB sufferers (Benoit et al., 2008). However, mycobacteria have developed strategies to avert a strong M1 response and the early secreted antigenic target protein 6 (ESAT6) expressed by $M$. tuberculosis has been shown to significantly reduce the innate immune response significantly. Binding of ESAT- 6 to TLR-2 prevented the downstream activation of NF- $\kappa$ B (Pathak et al., 2007).

A different line of research has shown Wnt6 signaling in granulomas induces arginase and downregulates TNF expression, driving a M2 polarization in a mouse model of $M$. tuberculosis infection (Schaale et al., 2013). This pathway and the entire Wnt network have been shown to be part of the conversation between pathogen and host and can be manipulated by M. tuberculosis (Villasenor et al., 2017). The alternative activation of macrophages is beneficial for the pathogen, since cellular Larginine supply is limited and an activation of Arg-1 can rapidly deplete its levels, reducing the impact of iNOS via substrate competition. Interestingly, abrogation of arginase in iNOSdeficient mice under hypoxic conditions in granulomas resulted in increased bacterial burden and strong lung pathology pointing to an additional role of Arg-1 in immune regulation (DuqueCorrea et al., 2014). However, macrophages under normal conditions can avoid undersupply of L-arginine by converting L-citrulline back to L-arginine, thus promoting their antimycobacterial activities (Rapovy et al., 2015). Notably, deficiency specifically in macrophage-expressed Arg1 resulted in a reduced M. tuberculosis burden and smaller cellular infiltrates in the lungs after aerosol infection (El Kasmi et al., 2008). Alternative activation has been demonstrated to result in reduced nitrosative stress of the pathogens (Kahnert et al., 2006). Likewise, IL-4 and IL-13 inhibited autophagy-induced killing of M. tuberculosis by macrophages (Harris et al., 2007).

\section{Leishmania major}

Resistance to experimental L. major infections is driven by a strong Th1 response and an aligned M1 polarization of macrophages (Reiner and Locksley, 1995; Tomiotto-Pellissier et al., 2018). The expression of iNOS and the presence of NO have been shown to be critical for the elimination of L. major (Green et al., 1990; Liew et al., 1990b; Diefenbach et al., 1998). However, the role of TNF in this inflammatory response has been revisited and it was shown that TNF, while acting as pro-inflammatory mediator supporting M1 polarization, also actively blocked M2 polarization in L. major infected $\mathrm{TNF}^{-/-}$mice (Schleicher et al., 2016). An analysis of skin lesions showed that TNF-deficient mice not only contained fewer $\mathrm{CD}_{11} \mathrm{~b}^{+}{ }_{\mathrm{iNOS}}{ }^{+}$cells than $\operatorname{did} \mathrm{WT}$ lesions but additionally almost all iNOS ${ }^{+}$cells co-expressed Arg1. This occurred only in around $50 \%$ of WT CD11b ${ }^{+}$iNOS $^{+}$cells. This overexpression of Arg1 in the absence of TNF resulted in a lack of tyrosine nitration in the lesion and the draining lymph nodes, which caused by a strongly reduced activity of NO in the tissue despite a presence of iNOS (Schleicher et al., 2016). Independent of the potential competition with NO during the acute stage, Arg1 has recently been reported to be dispensable for the resolution of cutaneous leishmaniasis (Paduch et al., 2019).

\section{CONCLUDING REMARKS}

While there is now broad agreement about the development and activation pathways of monocytes and macrophages, it is increasingly clear that we are not looking at one relatively homogenous population but a continuum of very different developmental states (Hume, 2015; Guilliams et al., 2018). Macrophage differentiation responds dynamically to environmental changes in vivo even under so called steady state conditions (Hume, 2015). Under inflammatory conditions this situation becomes even more fluid. Antigenic stimuli such as pathogens are highly dynamic and cytokines do not exist in isolation in inflamed tissues. Because the transcriptome of macrophages displays such high plasticity it has been accepted that various responses to environmental signals occur and consequently, various molecule signatures can co-exist and change rapidly. The example of a color wheel has been used where every combination of colors is possible (Mosser and Edwards, 2008) and this extension from polarization to spectrum model is now well supported experimentally (Xue et al., 2014).

As a consequence, the notion to define myeloid cell populations by only a few marker molecules has been challenged. Identifying combinations of key marker molecules that accurately characterize macrophage subpopulations and related dendritic cells in the in vivo context has been a major goal, but it is not fully supported by the transcriptional analysis of signature molecules (Gautier et al., 2012; Miller et al., 2012; Hume, 2015). Rather, new approaches using single cell transcriptomics are now revealing previously hidden insights in the heterogeneity of myeloid cell populations (Shalek et al., 2013, 2014) and can be used to better understand the behavior of tissue specific cell populations such as microglia (Li et al., 2019) or the cell specific changes that follow the conversation between immune cell and pathogen and that underlie the immune response (Avraham et al., 2015). Therefore, an analysis of in vivo models at a single cell level represents the ultimate challenge and the understanding of the regulation of transcriptional changes in response to a dynamic and complex environment is still in its infancy.

For many years, TNF has been acknowledged as an important pro-inflammatory cytokine that plays a clearly important yet still only vaguely defined role in the immune response. A puzzling observation has been the dominant part it plays in response to intracellular infections by bacteria and parasites where the humoral response is subservient. Recently, a new role of TNF in the biology of macrophages was demonstrated (Schleicher et al., 2016) and the importance of effective polarization was emphasized. A dysregulated macrophage polarization that leads to an ill-timed accumulation of M2 macrophages and as consequence a lack of proinflammatory mediators and effector molecules due to either absence or suppression of TNF could be an explanation for the increased sensitivity to this category of pathogens. Further research will be needed to gage the extent how an effective and timely macrophage polarization reigns 
in the early spread of pathogens and supports the general immune response.

\section{AUTHOR CONTRIBUTIONS}

XLi: original draft preparation. HK and XLiu: review, editing, and supervision. XLi and XLiu: funding acquisition. All authors contributed to the article and approved the submitted version.

\section{REFERENCES}

Allenbach, C., Launois, P., Mueller, C., and Tacchini-Cottier, F. (2008). An essential role for transmembrane TNF in the resolution of the inflammatory lesion induced by Leishmania major infection. Eur. J. Immunol. 38, 720-731. doi: $10.1002 /$ eji.200737662

Avraham, R., Haseley, N., Brown, D., Penaranda, C., Jijon, H. B., Trombetta, J. J., et al. (2015). Pathogen cell-to-cell variability drives heterogeneity in host immune responses. Cell 162, 1309-1321. doi: 10.1016/j.cell.2015.08.027

Bancroft, G. J., Sheehan, K. C., Schreiber, R. D., and Unanue, E. R. (1989). Tumor necrosis factor is involved in the T cell-independent pathway of macrophage activation in scid mice. J. Immunol. 143, 127-130.

Bean, A. G. D., Roach, D. R., Briscoe, H., France, M. P., Korner, H., Sedgwick, J. D., et al. (1999). Structural deficiencies in granuloma formation in TNF genetargeted mice underlie the heightened susceptibility to aerosol Mycobacterium tuberculosis infection, which is not compensated for by Lymphotoxin. J. Immunol. 162, 3504-3511.

Beckerman, K. P., Rogers, H. W., Corbett, J. A., Schreiber, R. D., Mcdaniel, M. L., and Unanue, E. R. (1993). Release of nitric oxide during the T cellindependent pathway of macrophage activation. Its role in resistance to Listeria monocytogenes. J. Immunol. 150, 888-895.

Beisiegel, M., Kursar, M., Koch, M., Loddenkemper, C., Kuhlmann, S., Zedler, U., et al. (2009). Combination of host susceptibility and virulence of Mycobacterium tuberculosis determines dual role of nitric oxide in the protection and control of inflammation. J. Infect. Dis. 199, 1222-1232. doi: $10.1086 / 597421$

Benoit, M., Desnues, B., and Mege, J. L. (2008). Macrophage polarization in bacterial infections. J. Immunol. 181, 3733-3739. doi: 10.4049/jimmunol.181. 6.3733

Bodro, M., and Paterson, D. L. (2013). Listeriosis in patients receiving biologic therapies. Eur. J. Clin. Microbiol. Infect. Dis. 32, 1225-1230. doi: 10.1007/ s10096-013-1873-1

Bogdan, C. (2015). Nitric oxide synthase in innate and adaptive immunity: an update. Trends Immunol. 36, 161-178. doi: 10.1016/j.it.2015.01.003

Bogdan, C., Gessner, A., Solbach, W., and Rollinghoff, M. (1996). Invasion, control and persistence of Leishmania parasites. Curr. Opin. Immunol. 8, 517-525. doi: 10.1016/s0952-7915(96)80040-9

Bogdan, C., Moll, H., Solbach, W., and Rollinghoff, M. (1990). Tumor necrosis factor-alpha in combination with interferon-gamma, but not with interleukin 4 activates murine macrophages for elimination of Leishmania major amastigotes. Eur. J. Immunol. 20, 1131-1135. doi: 10.1002/eji.1830200528

Bogdan, C., and Rollinghoff, M. (1998). The immune response to Leishmania: mechanisms of parasite control and evasion. Int. J. Parasitol. 28, 121-134. doi: 10.1016/s0020-7519(97)00169-0

Bongartz, T., Sutton, A. J., Sweeting, M. J., Buchan, I., Matteson, E. L., and Montori, V. (2006). Anti-TNF antibody therapy in rheumatoid arthritis and the risk of serious infections and malignancies: systematic review and meta-analysis of rare harmful effects in randomized controlled trials. JAMA 295, 2275-2285.

Boockvar, K. S., Granger, D. L., Poston, R. M., Maybodi, M., Washington, M. K., Hibbs, J. B., et al. (1994). Nitric oxide produced during murine listeriosis is protective. Infect. Immun. 62, 1089-1100. doi: 10.1128/iai.62.3.1089-1100.1994

Botha, T., and Ryffel, B. (2003). Reactivation of latent tuberculosis infection in TNF-deficient mice. J. Immunol. 171, 3110-3118. doi: 10.4049/jimmunol.171. 6.3110

Buchmeier, N. A., and Schreiber, R. D. (1985). Requirement of endogenous interferon-gamma production for resolution of Listeria monocytogenes

\section{FUNDING}

This work was supported by the National Natural Science Foundation of China under grants 81772908 and 81201368; Natural Science Foundation of the Anhui Education Department under grant KJ2019A0235; and Scientific Research Fund of Anhui Medical University under grant 2018xkj012.

infection. Proc. Natl. Acad. Sci. U.S.A. 82, 7404-7408. doi: 10.1073/pnas.82.21. 7404

Carswell, E. A., Old, L. J., Kassel, R. L., Green, S., Fiore, N., and Williamson, B. (1975). An endotoxin-induced serum factor that causes necrosis of tumors. Proc. Natl. Acad. Sci. U.S.A. 72, 3666-3670. doi: 10.1073/pnas.72.9.3666

Chacon-Salinas, R., Serafin-Lopez, J., Ramos-Payan, R., Mendez-Aragon, P., Hernandez-Pando, R., Van Soolingen, D., et al. (2005). Differential pattern of cytokine expression by macrophages infected in vitro with different Mycobacterium tuberculosis genotypes. Clin. Exp. Immunol. 140, 443-449. doi: 10.1111/j.1365-2249.2005.02797.x

Chan, J., Tanaka, K., Carroll, D., Flynn, J., and Bloom, B. R. (1995). Effects of nitric oxide synthase inhibitors on murine infection with Mycobacterium tuberculosis. Infect. Immun. 63, 736-740. doi: 10.1128/iai.63.2.736-740.1995

Cooper, A. M., Pearl, J. E., Brooks, J. V., Ehlers, S., and Orme, I. M. (2000). Expression of the nitric oxide synthase 2 gene is not essential for early control of Mycobacterium tuberculosis in the murine lung. Infect. Immun. 68, 6879-6882. doi: 10.1128/iai.68.12.6879-6882.2000

Cossart, P., and Mengaud, J. (1989). Listeria monocytogenes. A model system for the molecular study of intracellular parasitism. Mol. Biol. Med. 6, 463-474.

Dalton, D. K., Pitts-Meek, S., Keshav, S., Figari, I. S., Bradley, A., and Stewart, T. A. (1993). Multiple defects of immune cell function in mice with disrupted interferon-gamma genes. Science 259, 1739-1742. doi: 10.1126/science. 8456300

Desiderio, J. V., Kiener, P. A., Lin, P. F., and Warr, G. A. (1989). Protection of mice against Listeria monocytogenes infection by recombinant human tumor necrosis factor alpha. Infect. Immun. 57, 1615-1617. doi: 10.1128/iai.57.5.1615-1617. 1989

Diefenbach, A., Schindler, H., Donhauser, N., Lorenz, E., Laskay, T., Macmicking, J., et al. (1998). Type 1 interferon (IFN alpha/beta) and type 2 nitric oxide synthase regulate the innate immune response to a protozoan parasite. Immunity 8, 77-87. doi: 10.1016/s1074-7613(00)80460-4

Dixon, W., and Silman, A. (2006). Is there an association between anti-TNF monoclonal antibody therapy in rheumatoid arthritis and risk of malignancy and serious infection? Commentary on the meta-analysis by Bongartz et al. Arthritis Res. Ther. 8:111.

Dixon, W. G., Watson, K., Lunt, M., Hyrich, K. L., Silman, A. J., Symmons, D. P., et al. (2006). Rates of serious infection, including site-specific and bacterial intracellular infection, in rheumatoid arthritis patients receiving anti-tumor necrosis factor therapy: results from the British Society for Rheumatology Biologics Register. Arthritis Rheum. 54, 2368-2376. doi: 10.1002/art.21978

Duque-Correa, M. A., Kuhl, A. A., Rodriguez, P. C., Zedler, U., Schommer-Leitner, S., Rao, M., et al. (2014). Macrophage arginase-1 controls bacterial growth and pathology in hypoxic tuberculosis granulomas. Proc. Natl. Acad. Sci. U.S.A. 111, E4024-E4032.

Efimov, G. A., Kruglov, A. A., Tillib, S. V., Kuprash, D. V., and Nedospasov, S. A. (2009). Tumor necrosis factor and the consequences of its ablation in vivo. Mol. Immunol. 47, 19-27. doi: 10.1016/j.molimm.2009.01.007

Ehlers, S. (2005). Tumor necrosis factor and its blockade in granulomatous infections: differential modes of action of infliximab and etanercept? Clin. Infect. Dis. 41(Suppl. 3), S199-S203.

Ehlers, S., Kutsch, S., Ehlers, E. M., Benini, J., and Pfeffer, K. (2000). Lethal granuloma disintegration in mycobacteria-infected TNFRp55-/- mice is dependent on T cells and IL-12. J. Immunol. 165, 483-492. doi: 10.4049/ jimmunol.165.1.483

Ehrt, S., Schnappinger, D., Bekiranov, S., Drenkow, J., Shi, S., Gingeras, T. R., et al. (2001). Reprogramming of the macrophage transcriptome in response 
to interferon-gamma and Mycobacterium tuberculosis: signaling roles of nitric oxide synthase-2 and phagocyte oxidase. J. Exp. Med. 194, 1123-1140. doi: 10.1084/jem.194.8.1123

El Kasmi, K. C., Qualls, J. E., Pesce, J. T., Smith, A. M., Thompson, R. W., HenaoTamayo, M., et al. (2008). Toll-like receptor-induced arginase 1 in macrophages thwarts effective immunity against intracellular pathogens. Nat. Immunol. 9, 1399-1406. doi: 10.1038/ni.1671

Erickson, S. L., De Sauvage, F. J., Kikly, K., Carver-Moor, K., Pitts-Meek, S., Gillett, N., et al. (1994). Decreased sensitivity to tumour-necrosis factor but normal T-cell development in TNF receptor-2-deficient mice. Nature 372, 560-563. doi: $10.1038 / 372560 \mathrm{a} 0$

Fallahi-Sichani, M., Flynn, J. L., Linderman, J. J., and Kirschner, D. E. (2012). Differential risk of tuberculosis reactivation among anti-TNF therapies is due to drug binding kinetics and permeability. J. Immunol. 188, 3169-3178. doi: 10.4049/jimmunol.1103298

Flynn, J. L., Goldstein, M. M., Chan, J., Triebold, K. J., Pfeffer, K., Lowenstein, C. J., et al. (1995). Tumor necrosis factor-[alpha] is required in the protective immune response against Mycobacterium tuberculosis in mice. Immunity 2, 561-572. doi: 10.1016/1074-7613(95)90001-2

Fremond, C., Allie, N., Dambuza, I., Grivennikov, S., Yeremeev, V., Quesniaux, V., et al. (2005). Membrane TNF confers protection to acute mycobacterial infection. Respir. Res. 6:136.

Fromm, P. D., Kling, J., Mack, M., Sedgwick, J. D., and Korner, H. (2012). Loss of TNF signaling facilitates the development of a novel Ly-6C(low) macrophage population permissive for Leishmania major infection. J. Immunol. 188, 62586266. doi: 10.4049/jimmunol.1100977

Fromm, P. D., Kling, J. C., Remke, A., Bogdan, C., and Korner, H. (2015). Fatal leishmaniasis in the absence of TNF despite a strong Th1 response. Front. Microbiol. 6:1520. doi: 10.3389/fmicb.2015.01520

Gautier, E. L., Shay, T., Miller, J., Greter, M., Jakubzick, C., Ivanov, S., et al. (2012). Gene-expression profiles and transcriptional regulatory pathways that underlie the identity and diversity of mouse tissue macrophages. Nat. Immunol. 13, 1118-1128. doi: 10.1038/ni.2419

Gellin, B. G., and Broome, C. V. (1989). Listeriosis. JAMA 261, 1313-1320.

Getahun, H., Matteelli, A., Chaisson, R. E., and Raviglione, M. (2015). Latent Mycobacterium tuberculosis infection. N. Engl. J. Med. 372, 2127-2135.

Glaser, P., Frangeul, L., Buchrieser, C., Rusniok, C., Amend, A., Baquero, F., et al. (2001). Comparative genomics of Listeria species. Science 294, 849-852.

Gordon, S. (2003). Alternative activation of macrophages. Nat. Rev. Immunol. 3, 23-35.

Gordon, S., and Martinez, F. O. (2010). Alternative activation of macrophages: mechanism and functions. Immunity 32, 593-604. doi: 10.1016/j.immuni.2010. 05.007

Green, S. J., Crawford, R. M., Hockmeyer, J. T., Meltzer, M. S., and Nacy, C. A. (1990). Leishmania major amastigotes initiate the L-arginine-dependent killing mechanism in IFN-gamma-stimulated macrophages by induction of tumor necrosis factor-alpha. J. Immunol. 145, 4290-4297.

Grivennikov, S. I., Tumanov, A. V., Liepinsh, D. J., Kruglov, A. A., Marakusha, B. I., Shakhov, A. N., et al. (2005). Distinct and nonredundant in vivo functions of TNF produced by $\mathrm{T}$ cells and macrophages/neutrophils: protective and deleterious effects. Immunity 22, 93-104. doi: 10.1016/s1074-7613(04)00379-6

Guedes-Barbosa, L. S., Pereira, Da Costa, I., Fernandes, V., Henrique Da Mota, L. M., De Menezes, I., et al. (2013). Leishmaniasis during anti-tumor necrosis factor therapy: report of 4 cases and review of the literature (additional 28 cases). Semin. Arthritis Rheum. 43, 152-157. doi: 10.1016/j.semarthrit.2013.01.006

Guilliams, M., Mildner, A., and Yona, S. (2018). Developmental and functional heterogeneity of monocytes. Immunity 49, 595-613. doi: 10.1016/j.immuni. 2018.10.005

Guirado, E., and Schlesinger, L. S. (2013). Modeling the Mycobacterium tuberculosis granuloma - the critical battlefield in host immunity and disease. Front. Immunol. 4:98. doi: 10.3389/fimmu.2013.00098

Harris, J., De Haro, S. A., Master, S. S., Keane, J., Roberts, E. A., Delgado, M., et al. (2007). T helper 2 cytokines inhibit autophagic control of intracellular Mycobacterium tuberculosis. Immunity 27, 505-517. doi: 10.1016/j.immuni. 2007.07.022

Havell, E. A. (1987). Production of tumor necrosis factor during murine listeriosis. J. Immunol. 139, 4225-4231.
Hoffmann, A., Levchenko, A., Scott, M. L., and Baltimore, D. (2002). The IkappaBNF-kappaB signaling module: temporal control and selective gene activation. Science 298, 1241-1245. doi: 10.1126/science.1071914

Hu, S., Marshall, C., Darby, J., Wei, W., Lyons, A. B., and Korner, H. (2018). Absence of tumor necrosis factor supports alternative activation of macrophages in the liver after infection with Leishmania major. Front. Immunol. 9:1. doi: 10.3389/fimmu.2018.00001

Hu, S., Wei, W., and Korner, H. (2017). The role of monocytes in models of infection by protozoan parasites. Mol. Immunol. 88, 174-184. doi: 10.1016/j. molimm.2017.06.020

Hume, D. A. (2015). The many alternative faces of macrophage activation. Front. Immunol. 6:370. doi: 10.3389/fimmu.2015.00370

Jacobs, M., Brown, N., Allie, N., Chetty, K., and Ryffel, B. (2000). Tumor necrosis factor receptor 2 plays a minor role for mycobacterial immunity. Pathobiology 68, 68-75. doi: 10.1159/000028116

Kahnert, A., Seiler, P., Stein, M., Bandermann, S., Hahnke, K., Mollenkopf, H., et al. (2006). Alternative activation deprives macrophages of a coordinated defense program to Mycobacterium tuberculosis. Eur. J. Immunol. 36, 631-647. doi: 10.1002/eji.200535496

Kalliolias, G. D., and Ivashkiv, L. B. (2016). TNF biology, pathogenic mechanisms and emerging therapeutic strategies. Nat. Rev. Rheumatol. 12, 49-62. doi: 10.1038/nrrheum.2015.169

Kaufmann, S. H. (2001). How can immunology contribute to the control of tuberculosis? Nat. Rev. Immunol. 1, 20-30. doi: 10.1038/35095558

Kaufmann, S. H., Cole, S. T., Mizrahi, V., Rubin, E., and Nathan, C. (2005). Mycobacterium tuberculosis and the host response. J. Exp. Med. 201, 16931697.

Kaye, P. M., and Aebischer, T. (2011). Visceral leishmaniasis: immunology and prospects for a vaccine. Clin. Microbiol. Infect. 17, 1462-1470. doi: 10.1111/j. 1469-0691.2011.03610.x

Keane, J., Gershon, S., Wise, R. P., Mirabile-Levens, E., Kasznica, J., Schwieterman, W. D., et al. (2001). Tuberculosis associated with infliximab, a tumor necrosis factor alpha-neutralizing agent. N. Engl. J. Med. 345, 1098-1104. doi: 10.1056/ nejmoa011110

Kollias, G. (2005). TNF pathophysiology in murine models of chronic inflammation and autoimmunity. Semin. Arthritis Rheum. 34, 3-6. doi: 10. 1016/j.semarthrit.2005.01.002

Kollias, G., Douni, E., Kassiotis, G., and Kontoyiannis, D. (1999). On the role of tumor necrosis factor and receptors in models of multiorgan failure, rheumatoid arthritis, multiple sclerosis and inflammatory bowel disease. Immunol. Rev. 169, 175-194. doi: 10.1111/j.1600-065x.1999.tb01315.x

Körner, H., Cook, M., Riminton, D. S., Lemckert, F. A., Hoek, R. M., Ledermann, B., et al. (1997). Distinct roles for lymphotoxin-alpha and tumor necrosis factor in organogenesis and spatial organization of lymphoid tissue. Eur. J. Immunol. 27, 2600-2609. doi: 10.1002/eji.1830271020

Körner, H., and Sedgwick, J. D. (1996). Tumour necrosis factor and lymphotoxin: molecular aspects and role in tissue-specific autoimmunity. Immunol. Cell Biol. 74, 465-472. doi: 10.1038/icb.1996.77

Kratochvill, F., Neale, G., Haverkamp, J. M., Van De Velde, L. A., Smith, A. M., Kawauchi, D., et al. (2015). TNF counterbalances the emergence of M2 tumor macrophages. Cell Rep. 12, 1902-1914. doi: 10.1016/j.celrep.2015.08.033

Kurihara, T., Warr, G., Loy, J., and Bravo, R. (1997). Defects in macrophage recruitment and host defense in mice lacking the CCR2 chemokine receptor. J. Exp. Med. 186, 1757-1762. doi: 10.1084/jem.186.10.1757

Kusnadi, A., Park, S. H., Yuan, R., Pannellini, T., Giannopoulou, E., Oliver, D., et al. (2019). The cytokine TNF promotes transcription factor SREBP activity and binding to inflammatory genes to activate macrophages and limit tissue repair. Immunity 51, 241-257.e9. doi: 10.1016/j.immuni.2019.06.005

Laskay, T., Van Zandbergen, G., and Solbach, W. (2003). Neutrophil granulocytesTrojan horses for Leishmania major and other intracellular microbes? Trends Microbiol. 11, 210-214. doi: 10.1016/s0966-842x(03)00075-1

Leenen, P. J., Canono, B. P., Drevets, D. A., Voerman, J. S., and Campbell, P. A. (1994). TNF-alpha and IFN-gamma stimulate a macrophage precursor cell line to kill Listeria monocytogenes in a nitric oxide-independent manner. J. Immunol. 153, 5141-5147.

Li, Q., Cheng, Z., Zhou, L., Darmanis, S., Neff, N. F., Okamoto, J., et al. (2019). Developmental heterogeneity of microglia and brain myeloid cells revealed by 
deep single-cell RNA sequencing. Neuron 101, 207-223.e10. doi: 10.1016/j. neuron.2018.12.006

Li, X., Lyons, A. B., Woods, G. M., and Korner, H. (2017). The absence of TNF permits myeloid arginase 1 expression in experimental L. monocytogenes infection. Immunobiology 222, 913-917. doi: 10.1016/j.imbio.2017.05.012

Liew, F. Y., Li, Y., and Millott, S. (1990a). Tumor necrosis factor-alpha synergizes with IFN-gamma in mediating killing of Leishmania major through the induction of nitric oxide. J. Immunol. 145, 4306-4310.

Liew, F. Y., Millott, S., Parkinson, C., Palmer, R. M., and Moncada, S. (1990b). Macrophage killing of Leishmania parasite in vivo is mediated by nitric oxide from L-arginine. J. Immunol. 144, 4794-4797.

Liew, F. Y., Li, Y., Yang, D. M., Severn, A., and Cox, F. E. (1991). TNF-alpha reverses the disease-exacerbating effect of subcutaneous immunization against murine cutaneous leishmaniasis. Immunology 74, 304-309.

Listing, J., Strangfeld, A., Kary, S., Rau, R., Von Hinueber, U., Stoyanova-Scholz, M., et al. (2005). Infections in patients with rheumatoid arthritis treated with biologic agents. Arthritis Rheum. 52, 3403-3412. doi: 10.1002/art.21386

Lugering, A., Schmidt, M., Lugering, N., Pauels, H. G., Domschke, W., and Kucharzik, T. (2001). Infliximab induces apoptosis in monocytes from patients with chronic active Crohn's disease by using a caspase-dependent pathway. Gastroenterology 121, 1145-1157. doi: 10.1053/gast.2001.28702

Macmicking, J. D., North, R. J., Lacourse, R., Mudgett, J. S., Shah, S. K., and Nathan, C. F. (1997). Identification of nitric oxide synthase as a protective locus against tuberculosis. Proc. Natl. Acad. Sci. U.S.A. 94, 5243-5248. doi: 10.1073/pnas.94.10.5243

Mannel, D. N., Moore, R. N., and Mergenhagen, S. E. (1980). Macrophages as a source of tumoricidal activity (tumor-necrotizing factor). Infect. Immun. 30, 523-530.

Marcoval, J., Penin, R. M., Sabe, N., Valenti-Medina, F., Bonfill-Orti, M., and Martinez-Molina, L. (2017). Cutaneous leishmaniasis associated with antitumour necrosis factor-alpha drugs: an emerging disease. Clin. Exp. Dermatol. 42,331-334. doi: 10.1111/ced.13061

Martinez, F. O., Helming, L., Milde, R., Varin, A., Melgert, B. N., Draijer, C., et al. (2013). Genetic programs expressed in resting and IL-4 alternatively activated mouse and human macrophages: similarities and differences. Blood 121, e57-e69. doi: 10.1182/blood-2012-06-436212

Miller, J. C., Brown, B. D., Shay, T., Gautier, E. L., Jojic, V., Cohain, A., et al. (2012). Deciphering the transcriptional network of the dendritic cell lineage. Nat. Immunol. 13, 888-899. doi: 10.1038/ni.2370

Mohan, V. P., Scanga, C. A., Yu, K., Scott, H. M., Tanaka, K. E., Tsang, E., et al. (2001). Effects of tumor necrosis factor alpha on host immune response in chronic persistent tuberculosis: possible role for limiting pathology. Infect. Immun. 69, 1847-1855. doi: 10.1128/iai.69.3.1847-1855.2001

Mosser, D. M., and Edwards, J. P. (2008). Exploring the full spectrum of macrophage activation. Nat. Rev. Immunol. 8, 958-969. doi: 10.1038/nri2448

Murray, P. J. (2017). Macrophage polarization. Annu. Rev. Physiol. 79, 541-566.

Murray, P. J., Allen, J. E., Biswas, S. K., Fisher, E. A., Gilroy, D. W., Goerdt, S., et al. (2014). Macrophage activation and polarization: nomenclature and experimental guidelines. Immunity 41, 14-20. doi: 10.1016/j.immuni.2014. 06.008

Nashleanas, M., Kanaly, S., and Scott, P. (1998). Control of Leishmania major infection in mice lacking TNF receptors. J. Immunol. 160, 5506-5513.

Neumayr, A. L., Morizot, G., Visser, L. G., Lockwood, D. N., Beck, B. R., Schneider, S., et al. (2013). Clinical aspects and management of cutaneous leishmaniasis in rheumatoid patients treated with TNF-alpha antagonists. Travel Med. Infect. Dis. 11, 412-420. doi: 10.1016/j.tmaid.2013.05.003

O’garra, A., Redford, P. S., Mcnab, F. W., Bloom, C. I., Wilkinson, R. J., and Berry, M. P. (2013). The immune response in tuberculosis. Annu. Rev. Immunol. 31, 475-527.

Old, L. J. (1985). Tumor necrosis factor (TNF). Science 230, 630-632.

Olekhnovitch, R., Ryffel, B., Muller, A. J., and Bousso, P. (2014). Collective nitric oxide production provides tissue-wide immunity during Leishmania infection. J. Clin. Invest. 124, 1711-1722. doi: 10.1172/jci72058

Olleros, M. L., Guler, R., Corazza, N., Vesin, D., Eugster, H. P., Marchal, G., et al. (2002). Transmembrane TNF induces an efficient cell-mediated immunity and resistance to Mycobacterium bovis bacillus Calmette-Guerin infection in the absence of secreted TNF and lymphotoxin-alpha. J. Immunol. 168, 3394-3401. doi: 10.4049/jimmunol.168.7.3394
Paduch, K., Debus, A., Rai, B., Schleicher, U., and Bogdan, C. (2019). Resolution of cutaneous leishmaniasis and persistence of Leishmania major in the absence of arginase 1. J. Immunol. 202, 1453-1464. doi: 10.4049/jimmunol.1801249

Pasparakis, M., Alexopoulou, L., Episkopou, V., and Kollias, G. (1996). Immune and inflammatory responses in TNF alpha-deficient mice: a critical requirement for TNF alpha in the formation of primary B cell follicles, follicular dendritic cell networks and germinal centers, and in the maturation of the humoral immune response. J. Exp. Med. 184, 1397-1411. doi: 10.1084/jem.184.4.1397

Pathak, S. K., Basu, S., Basu, K. K., Banerjee, A., Pathak, S., Bhattacharyya, A., et al. (2007). Direct extracellular interaction between the early secreted antigen ESAT-6 of Mycobacterium tuberculosis and TLR2 inhibits TLR signaling in macrophages. Nat. Immunol. 8, 610-618. doi: 10.1038/ni1468

Pearson, R. D., Wheeler, D. A., Harrison, L. H., and Kay, H. D. (1983). The immunobiology of leishmaniasis. Rev. Infect. Dis. 5, 907-927.

Peters, N. C., Egen, J. G., Secundino, N., Debrabant, A., Kimblin, N., Kamhawi, S., et al. (2008). In vivo imaging reveals an essential role for neutrophils in leishmaniasis transmitted by sand flies. Science 321, 970-974. doi: 10.1126/ science.1159194

Pfeffer, K., Matsuyama, T., Kündig, T. M., Wakeham, A., Kishihara, K., Shahinian, A., et al. (1993). Mice deficient for the $55 \mathrm{kd}$ tumor necrosis factor receptor are resistant to endotoxic shock, yet succumb to L. monocytogenes infection. Cell 73, 457-467. doi: 10.1016/0092-8674(93)90134-c

Rapovy, S. M., Zhao, J., Bricker, R. L., Schmidt, S. M., Setchell, K. D., and Qualls, J. E. (2015). Differential requirements for l-citrulline and l-arginine during antimycobacterial macrophage activity. J. Immunol. 195, 3293-3300. doi: 10. 4049/jimmunol.1500800

Rath, M., Muller, I., Kropf, P., Closs, E. I., and Munder, M. (2014). Metabolism via arginase or nitric oxide synthase: two competing arginine pathways in macrophages. Front. Immunol. 5:532. doi: 10.3389/fimmu.2014.00532

Ready, P. D. (2014). Epidemiology of visceral leishmaniasis. Clin. Epidemiol. 6, 147-154.

Redente, E. F., Higgins, D. M., Dwyer-Nield, L. D., Orme, I. M., GonzalezJuarrero, M., and Malkinson, A. M. (2010). Differential polarization of alveolar macrophages and bone marrow-derived monocytes following chemically and pathogen-induced chronic lung inflammation. J. Leukoc. Biol. 88, 159-168. doi: $10.1189 / \mathrm{jlb} .0609378$

Reiner, S. L., and Locksley, R. M. (1995). The regulation of immunity to Leishmania major. Annu. Rev. Immunol. 13, 151-177. doi: 10.1146/annurev.iy.13.040195. 001055

Reithinger, R., Dujardin, J. C., Louzir, H., Pirmez, C., Alexander, B., and Brooker, S. (2007). Cutaneous leishmaniasis. Lancet Infect. Dis. 7, 581-596.

Rothe, J., Lesslauer, W., Lotscher, H., Lang, Y., Koebel, P., Kontgen, F., et al. (1993). Mice lacking the tumour necrosis factor receptor 1 are resistant to IMFmediated toxicity but highly susceptible to infection by Listeria monocytogenes. Nature 364, 798-802. doi: 10.1038/364798a0

Sacks, D. L., and Perkins, P. V. (1984). Identification of an infective state of Leishmania promastigotes. Science 223, 1417-1419. doi: 10.1126/science. 6701528

Saunders, B. M., Tran, S., Ruuls, S., Sedgwick, J. D., Briscoe, H., and Britton, W. J. (2005). Transmembrane TNF is sufficient to initiate cell migration and granuloma formation and provide acute, but not long-term, control of Mycobacterium tuberculosis infection. J. Immunol. 174, 4852-4859. doi: 10. 4049/jimmunol.174.8.4852

Scanga, C. A., Mohan, V. P., Yu, K., Joseph, H., Tanaka, K., Chan, J., et al. (2000). Depletion of CD4(+) T cells causes reactivation of murine persistent tuberculosis despite continued expression of interferon gamma and nitric oxide synthase 2. J. Exp. Med. 192, 347-358. doi: 10.1084/jem.192.3.347

Schaale, K., Brandenburg, J., Kispert, A., Leitges, M., Ehlers, S., and Reiling, N. (2013). Wnt6 is expressed in granulomatous lesions of Mycobacterium tuberculosis-infected mice and is involved in macrophage differentiation and proliferation. J. Immunol. 191, 5182-5195. doi: 10.4049/jimmunol.12 01819

Schleicher, U., Paduch, K., Debus, A., Obermeyer, S., Konig, T., Kling, J. C., et al. (2016). TNF-mediated restriction of arginase 1 expression in myeloid cells triggers type 2 no synthase activity at the site of infection. Cell Rep. 15, 1062-1075. doi: 10.1016/j.celrep.2016.04.001

Schuchat, A., Swaminathan, B., and Broome, C. V. (1991). Epidemiology of human listeriosis. Clin. Microbiol. Rev. 4, 169-183. doi: 10.1128/cmr.4.2.169-183.1991 
Sedgwick, J. D., Riminton, D. S., Cyster, J. G., and Körner, H. (2000). Tumor necrosis factor: a master-regulator of leukocyte movement. Immunol. Today 21, 110-113. doi: 10.1016/s0167-5699(99)01573-x

Seiler, P., Aichele, P., Bandermann, S., Hauser, A. E., Lu, B., Gerard, N. P., et al. (2003). Early granuloma formation after aerosol Mycobacterium tuberculosis infection is regulated by neutrophils via CXCR3-signaling chemokines. Eur. J. Immunol. 33, 2676-2686. doi: 10.1002/eji.2003 23956

Serbina, N. V., Salazar-Mather, T. P., Biron, C. A., Kuziel, W. A., and Pamer, E. G. (2003). TNF/iNOS-producing dendritic cells mediate innate immune defense against bacterial infection. Immunity 19, 59-70. doi: 10.1016/s1074-7613(03) 00171-7

Shalek, A. K., Satija, R., Adiconis, X., Gertner, R. S., Gaublomme, J. T., Raychowdhury, R., et al. (2013). Single-cell transcriptomics reveals bimodality in expression and splicing in immune cells. Nature 498, 236-240. doi: 10.1038/ nature 12172

Shalek, A. K., Satija, R., Shuga, J., Trombetta, J. J., Gennert, D., Lu, D., et al. (2014). Single-cell RNA-seq reveals dynamic paracrine control of cellular variation. Nature 510, 363-369. doi: 10.1038/nature13437

Shiloh, M. U., Macmicking, J. D., Nicholson, S., Brause, J. E., Potter, S., Marino, M., et al. (1999). Phenotype of mice and macrophages deficient in both phagocyte oxidase and inducible nitric oxide synthase. Immunity 10, 29-38. doi: 10.1016/ s1074-7613(00)80004-7

Slifman, N. R., Gershon, S. K., Lee, J. H., Edwards, E. T., and Braun, M. M. (2003). Listeria monocytogenes infection as a complication of treatment with tumor necrosis factor alpha-neutralizing agents. Arthritis Rheum. 48, 319-324. doi: $10.1002 /$ art. 10758

Stenger, S., Donhauser, N., Thuring, H., Rollinghoff, M., and Bogdan, C. (1996). Reactivation of latent leishmaniasis by inhibition of inducible nitric oxide synthase. J. Exp. Med. 183, 1501-1514. doi: 10.1084/jem.183.4.1501

Stenger, S., Thuring, H., Rollinghoff, M., and Bogdan, C. (1994). Tissue expression of inducible nitric oxide synthase is closely associated with resistance to Leishmania major. J. Exp. Med. 180, 783-793. doi: 10.1084/jem.180. 3.783

Theisen, E., and Sauer, J. D. (2016). Listeria monocytogenes and the inflammasome: from cytosolic bacteriolysis to tumor immunotherapy. Curr. Top. Microbiol. Immunol. 397, 133-160. doi: 10.1007/978-3-319-41171-2_7

Tilney, L. G., and Portnoy, D. A. (1989). Actin filaments and the growth, movement, and spread of the intracellular bacterial parasite, Listeria monocytogenes. J. Cell Biol. 109, 1597-1608. doi: 10.1083/jcb.109.4.1597

Titus, R. G., Sherry, B., and Cerami, A. (1989). Tumor necrosis factor plays a protective role in experimental murine cutaneous leishmaniasis. J. Exp. Med. 170, 2097-2104. doi: 10.1084/jem.170.6.2097

Tomiotto-Pellissier, F., Bortoleti, B., Assolini, J. P., Goncalves, M. D., Carloto, A. C. M., Miranda-Sapla, M. M., et al. (2018). Macrophage polarization in leishmaniasis: broadening horizons. Front. Immunol. 9:2529. doi: 10.3389/ fimmu.2018.02529

Torres, D., Janot, L., Quesniaux, V. F. J., Grivennikov, S. I., Maillet, I., Sedgwick, J. D., et al. (2005). Membrane tumor necrosis factor confers partial protection to Listeria infection. Am. J. Pathol. 167, 1677-1687. doi: 10.1016/s0002-9440(10) 61250-3
Tripp, C. S., Wolf, S. F., and Unanue, E. R. (1993). Interleukin 12 and tumor necrosis factor alpha are costimulators of interferon gamma production by natural killer cells in severe combined immunodeficiency mice with listeriosis, and interleukin 10 is a physiologic antagonist. Proc. Natl. Acad. Sci. U.S.A. 90, 3725-3729. doi: 10.1073/pnas.90.8.3725

Van Den Brande, J. M., Braat, H., Van Den Brink, G. R., Versteeg, H. H., Bauer, C. A., Hoedemaeker, I., et al. (2003). Infliximab but not etanercept induces apoptosis in lamina propria T-lymphocytes from patients with Crohn's disease. Gastroenterology 124, 1774-1785. doi: 10.1016/s0016-5085(03)00382-2

Van Zandbergen, G., Klinger, M., Mueller, A., Dannenberg, S., Gebert, A., Solbach, W., et al. (2004). Cutting edge: neutrophil granulocyte serves as a vector for Leishmania entry into macrophages. J. Immunol. 173, 6521-6525. doi: 10.4049/ jimmunol.173.11.6521

Varol, C., Mildner, A., and Jung, S. (2015). Macrophages: development and tissue specialization. Annu. Rev. Immunol. 33, 643-675. doi: 10.1146/annurevimmunol-032414-112220

Vazquez-Boland, J. A., Kuhn, M., Berche, P., Chakraborty, T., Dominguez-Bernal, G., Goebel, W., et al. (2001). Listeria pathogenesis and molecular virulence determinants. Clin. Microbiol. Rev. 14, 584-640.

Vidal, S. M., Malo, D., Vogan, K., Skamene, E., and Gros, P. (1993). Natural resistance to infection with intracellular parasites: isolation of a candidate for Bcg. Cell 73, 469-485. doi: 10.1016/0092-8674(93)90135-d

Vieira, L. Q., Goldschmidt, M., Nashleanas, M., Pfeffer, K., Mak, T., and Scott, P. (1996). Mice lacking the TNF receptor p55 fail to resolve lesions caused by infection with Leishmania major, but control parasite replication. J. Immunol. $157,827-835$.

Villasenor, T., Madrid-Paulino, E., Maldonado-Bravo, R., Urban-Aragon, A., Perez-Martinez, L., and Pedraza-Alva, G. (2017). Activation of the Wnt pathway by Mycobacterium tuberculosis: a Wnt-Wnt situation. Front. Immunol. 8:50. doi: 10.3389/fimmu.2017.00050

Wilhelm, P., Ritter, U., Labbow, S., Donhauser, N., Röllinghoff, M., Bogdan, C., et al. (2001). Rapidly fatal leishmaniasis in resistant C57BL/6 mice lacking TNF. J. Immunol. 166, 4012-4019. doi: 10.4049/jimmunol.166.6.4012

Xue, J., Schmidt, S. V., Sander, J., Draffehn, A., Krebs, W., Quester, I., et al. (2014). Transcriptome-based network analysis reveals a spectrum model of human macrophage activation. Immunity 40, 274-288. doi: 10.1016/j.immuni.2014. 01.006

Zanger, P., Kotter, I., Kremsner, P. G., and Gabrysch, S. (2012). Tumor necrosis factor alpha antagonist drugs and leishmaniasis in Europe. Clin. Microbiol. Infect. 18, 670-676. doi: 10.1111/j.1469-0691.2011.03674.x

Conflict of Interest: The authors declare that the research was conducted in the absence of any commercial or financial relationships that could be construed as a potential conflict of interest.

Copyright (c) $2020 \mathrm{Li}$, Körner and Liu. This is an open-access article distributed under the terms of the Creative Commons Attribution License (CC BY). The use, distribution or reproduction in other forums is permitted, provided the original author(s) and the copyright owner(s) are credited and that the original publication in this journal is cited, in accordance with accepted academic practice. No use, distribution or reproduction is permitted which does not comply with these terms. 